\title{
Prevalence of substance use amongst people living with human immunodeficiency virus who attend primary healthcare services in Mthatha, South Africa
}

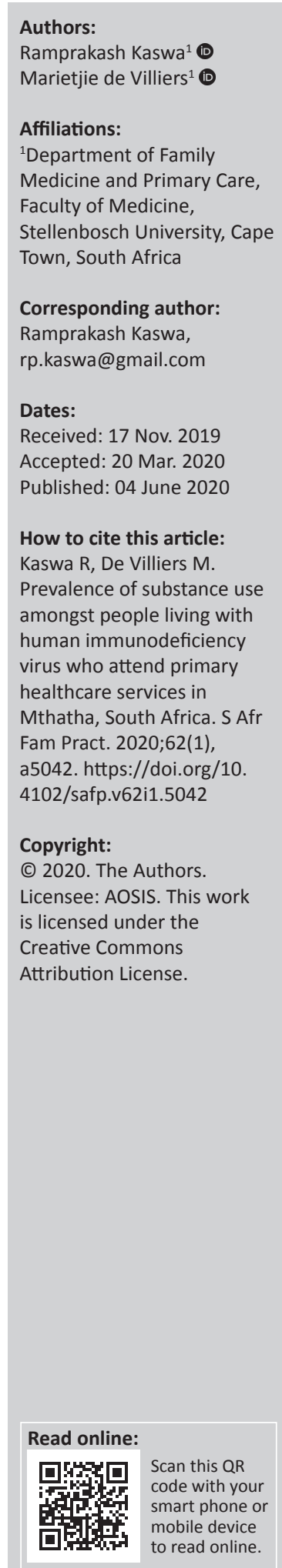

Background: About $13.3 \%$ of the South African population use some kind of substance during their lifetime. The incidence of substance use disorders is twice the global average. The use of various substances amongst people living with human immunodeficiency virus (PLWH) has increased tremendously in recent years. The growing culture of substance use amongst PLWH is a serious threat adding to the human immunodeficiency virus (HIV) epidemic and is likely to compromise the continuity of HIV care.

Methods: A cross-sectional descriptive survey recruited adult PLWH who attended primary healthcare (PHC) services in Mthatha between 15 March and 15 April 2018. The Alcohol, Smoking and Substance Involvement Screening Test questionnaire (ASSIST), a tool validated by the World Health Organization, was used for data collection.

Results: Out of a total 347 participants, 53\% reported lifetime substance use and 32\% admitted current use of a substance. Alcohol was the most common substance reported, followed by tobacco and cannabis. The majority of participants were female (75.2\%), unemployed (70.8\%), had secondary school-level education (85.2\%) and a per capita household income below the national food poverty line $(75 \%)$. The mean age of the participants was 37.9 years (standard deviation $[S D] \pm 10.33$ ); this was marginally higher for male (39.9 years; $\mathrm{SD} \pm 10.92)$ than female (37.2 years; $\mathrm{SD} \pm 10.06)$ participants.

Conclusion: This study has shown that there is a high prevalence of lifetime and current alcohol abuse amongst PLWH who make use of PHC services in the Mthatha area of South Africa. Of particular concern are the strong pointers towards younger people and males.

Keywords: Alcohol, Smoking and Substance Involvement Screening Test questionnaire; ASSIST; HIV; primary healthcare; PHC; people living with HIV; PLWH; substance.

\section{Introduction}

Globally, a quarter of a billion, or 1 in 20 people between the ages of 15 and 64 years, used a substance at least once in 2016. ${ }^{1}$ Substance abuse is widely defined as the harmful and hazardous use of tobacco, alcohol and psychotic substances. ${ }^{2}$ An estimated 31 million people who use substances suffer from substance dependency. The global estimated prevalence of substance use is $5.2 \%$ and the rate has been steady since $2011 .{ }^{1}$ About $0.6 \%$ of the global adult population suffers from substance dependency. ${ }^{1,3}$ Globally, cannabis (dagga) is the most commonly used substance, followed by amphetamine and opioids. Substance use and dependence have become a global concern. ${ }^{3}$

About $13.3 \%$ of the South African population uses at least one substance during their lifetime. The prevalence of substance use disorders is twice the global average. Alcohol is the most commonly used substance in South Africa, followed by tobacco and cannabis. About $7.06 \%$ of the population uses a narcotic substance at some stage in their lifetime and one in 14 uses it regularly. Inhalant substances are more popular amongst the youth and cannabis is the substance of choice, followed by methamphetamine (tik), amphetamine and heroin. ${ }^{4,5}$

Globally, the prevalence of substance use amongst people living with HIV (PLWH) is reported to be much higher than amongst the general population. In North America, an estimated 70\% of PLWH practise substance use. ${ }^{6,7}$ Hartzler et al. reported that $48 \%$ of the PLWH population in the United States use at least one substance and $20 \%$ of them use multiple substances. Cannabis is the most common substance reported amongst PLWH, followed by alcohol and amphetamine. ${ }^{8}$

Substance use amongst PLWH is emerging as a health syndemic (coexistence of HIV and substance use). The substance use epidemic is associated with delayed HIV diagnosis and increased 
transmission risk behaviour. The coexistence of substance use and HIV has negative consequences on the continuity of HIV care. ${ }^{9}$ Substance use has a complex relationship with HIV and has a detrimental effect on transmission, linkage to care, adherence to treatment and retention in care. Despite widespread availability of antiretroviral therapy (ART), the PLWH who undertook substance use had increased morbidity and mortality from HIV- and non-HIV-related causes. ${ }^{10}$ Granich et al. reported that substance use blunts the effectiveness of the universal test and treat (UTT) approach for HIV transmission. ${ }^{11}$ Substance users amongst PLWH often fail to attend HIV care despite early diagnosis. Even after linkage to care, a poor adherence rate is reported amongst PLWH who use substances. The increasing trend of substance use is further compromising the HIV linkage to care and adherence to anti-retroviral therapy. Substance use amongst PLWH is associated with a high viral load that leads to an increased HIV transmission rate, as well as perceived poor quality of life. ${ }^{12,13}$

Primary healthcare (PHC) settings are the basic unit of healthcare service. It is an entry point for both communicable and non-communicable disease prevention, diagnosis and management. The PHC system is a gateway for integrated and comprehensive HIV care in South Africa. ${ }^{2,14}$ Recently, the UTT was rolled out through the PHC platform. The PHC is the first contact a person has with the health system where a range of health issues are addressed. The PHC settings provide an opportunity to address the substance use problem amongst PLWH. Screening of substance use at PHC could especially benefit the PLWH and enable them to make informed decisions on substance use management. ${ }^{15}$

Substance use is often under-diagnosed in PHC settings. Despite the substantial health and social impact of substance use on the continuity of HIV care, patients reporting to PHC settings are not consistently screened for substance use. ${ }^{14,15}$ Addressing substance use in the context of PHC settings could increase access to and retention of care. Primary prevention and early management of substance use have proven to have better outcomes than treating substance dependence. ${ }^{16}$ Because there is only a limited number of specialised health professionals and health facilities that manage substance dependency in South Africa, it is critical for PHC workers to identify and manage substance use early, at the level of PHC settings.

This study is part of a larger project with the overarching aim to evaluate the co-morbidity of HIV and substance use, and the response of PHC services to such patients in the Mthatha region of the Eastern Cape. This article reports on the prevalence of substance use amongst PLWH who attend PHC services in the Mthatha region of the Eastern Cape province. We specifically sought to determine the type of substances used by PHC users who are living with HIV.

\section{Methods}

This cross-sectional descriptive survey was conducted in King Sabata Dalindyebo (KSD) sub-district municipality in the Eastern Cape province of South Africa. The estimated population of KSD is about 451710 people living in 105240 households. ${ }^{17}$ Mthatha is the main town in the KSD subdistrict municipality. Most (98\%) of the population are isiXhosa-speaking and rural. It is one of the poorest districts in which most people depend on social welfare grants and state facilities for healthcare services; only an estimated $4.6 \%$ have medical insurance.

The healthcare services in the KSD sub-district are rendered by one central and one regional hospital, as well as five community health centres (CHCs) and 42 clinics. The catchment areas of three of these CHCs are Mthatha township and the remaining two are located in the outskirts of the township. These $\mathrm{CHC}$ were divided into two strata, based on geographic location and the catchment areas of the population. One $\mathrm{CHC}$ from each stratum was selected for the current study, namely, Ngangelizwe and Mbekweni CHC. Ngangelizwe is the biggest CHC serving the township community, and Mbekweni is the biggest CHC serving an area on the outskirts of the township. Mbekweni is situated $20 \mathrm{~km}$ away from Mthatha.

\section{Sample size}

The sample size was calculated with the help of a biostatistician. A sample size of 350 produced a $95 \%$ confidence interval (CI) with a width equal to $10 \%$ when the sample proportion was assumed to be $30 \%$ of the PLWH. According to KSD sub-district monthly statistics, an average of 4000 PLWH visited the two selected CHCs every month. Researchers targeted 1 month to collect data after calculating the average number of PLWH visiting the selected PHCs.

\section{Study participants}

The entire study population consisted of adult (18 years and older) HIV patients who visited PHC settings in the KSD district municipality between 15 March and 15 April 2018. According to KSD sub-district statistics, the number of adult HIV patients who visited PHC settings during this period was 7793. During the same period, 3492 adults attended HIV clinics at the two selected CHCs. A simple random sampling method was used to identify participants. Ten participants were selected from a list of 1 to 100 in order of arrival at the HIV clinic, using random numbers generated in an Excel spreadsheet from each $\mathrm{CHC}$ on a particular day. If a patient refused to participate, the immediate next number was used. Critically ill patients were excluded from the study. Participants who met the inclusion criteria were approached and invited to participate after giving written informed consent. The sampling frame for the current study is demonstrated in Figure 1 as a flow chart. 


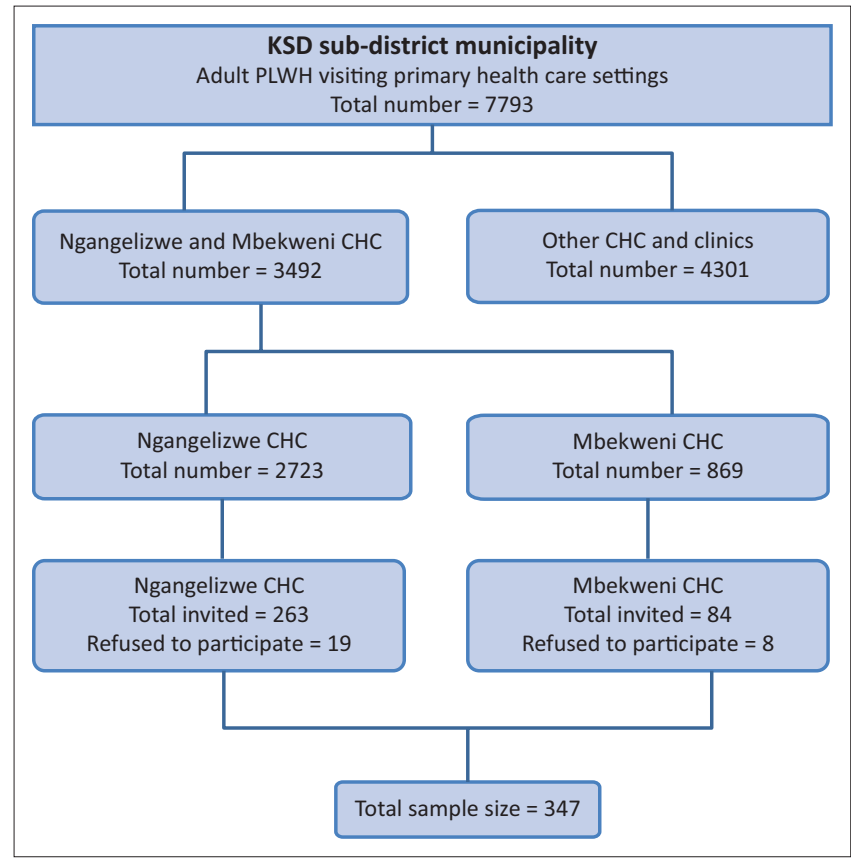

CHC, community health centre; KSD, King Sabata Dalindyebo; PLWH, people living with human immunodeficiency virus.

FIGURE 1: Sampling frame for people living with human immunodeficiency virus in King Sabata Dalindyebo sub-district municipality who visited primary healthcare settings between 15 March and 15 April 2018.

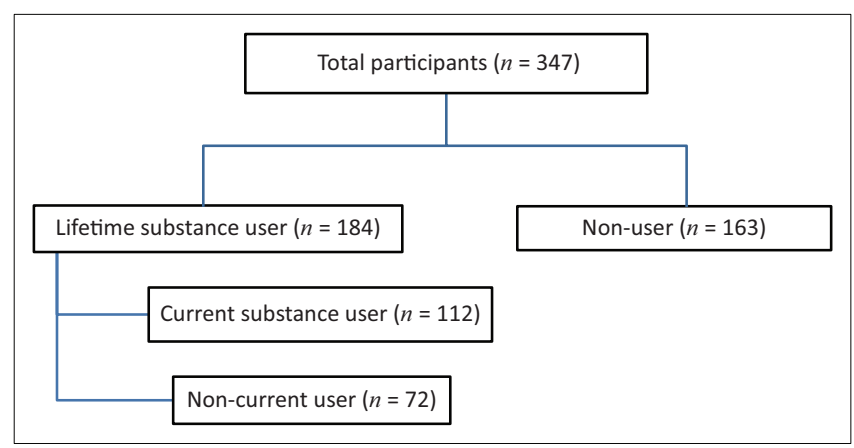

FIGURE 2: The distribution of participants in the current study.

\section{Data collection and analysis}

Trained research assistants administered a structured questionnaire to collect demographic data on age, gender, household income, cluster of differentiation 4 [CD4] and viral load. Substance use, type, duration and severity were measured by using the Alcohol, Smoking and Substance Involvement Screening Test (ASSIST) validated by the World Health Organization (WHO) ${ }^{18}$ It is a screening tool used for the measurement of tobacco, alcohol and other psychoactive substances used during the lifetime and in the past 3 months in PHC settings. The tool also measures the degree of substance use and dependence. The tool comprises eight questions. The first question asks about lifetime use of the following 10 commonly available substances: tobacco, alcohol, cannabis, cocaine, amphetamine-type stimulants, inhalants, sedatives, hallucinogens, opioids and other drugs. If the participant responds negatively to all substances in the first question, the interview is terminated. In case of endorsement of one or more substances during the lifetime, the participant proceeds to questions 2-5. These questions ask about the frequency of use, craving and frequency of health, social, legal or financial problems related to recent substance use. Questions 6 and 7 ask about lifetime substancerelated problems (expressed concern about substance use, failed attempt to control, failure to meet the expected obligation). Each question is rated from 0 for never to 5 points for daily use. Question 8 enquired about intravenous drug use. A total risk score calculated from the completed ASSIST interview was based on the sum of scores from questions 2-7. A risk category was assigned, indicating the risk for each substance queried (for alcohol: low $=0-10$; moderate $=11-26$; high $=27+$; for other substances: low $=0-3$; moderate $=4-26$, high $=27+$ ). The ASSIST risk categories determine the substance-related risk and the most appropriate intervention. ${ }^{15,16}$ The tool is validated for use in PHC settings and has previously been used in the South African context.

Two research assistants were recruited from outside the study community because of the sensitivity and stigma associated with substance use disclosed during the interview. The research assistants were retired nurses and fluent in both English and IsiXhosa. The research assistants attended a simulated patient training workshop for adoption of the standard procedure of the ASSIST tool. The data were collected simultaneously from both health centres. All interviews were conducted in English language in a private consulting room to prevent any interruption and to ensure privacy.

Each participant was assessed using the ASSIST tool, after obtaining written informed consent from participants. Data were entered on an Excel spreadsheet and every10th item on the sheet was double-checked for correctness. The data were analysed by biostatisticians. Statistical Package for Social Sciences (SPSS) version 18 was used. Frequency analysis was used to determine lifetime substances use as well as use during the past 3 months. The ASSIST risk score was calculated as described above and as a standard procedure for the ASSIST. Cross-tabulation between substance use (lifetime and past 3 months) and other demographic characteristics was analysed. The Pearson Chi-squared test was used for categorical data to evaluate any significant difference in the $(p<0.05)$ level observed.

\section{Ethical considerations}

The Health Research Ethics Committee (HREC) of Stellenbosch University approved the study (HREC reference number: S18/01/001). The study was also approved by the Department of Health, Eastern Cape (National Health Research Database [NHRD] reference number EC_201803_007), as well as the local health authorities.

\section{Results}

There were 347 PLWH (Figure 2) who participated in the study. The mean age was 37.9 years (standard deviation [SD] \pm 10.33$)$. This was slightly higher amongst male 
(39.9 years; $\mathrm{SD} \pm 10.92)$ than amongst female (37.2 years; SD $\pm 10.06)$ participants. The majority of participants were female $(75.2 \%)$, unemployed $(70.8 \%)$ and had secondary school-level education (85.2\%) and a per capita household income below the national food poverty line (75\%). About two-thirds of participants disclosed their HIV status to close family members. Table 1 presents the demographic and clinical characteristics of lifetime and current substance use amongst PLWH.

The prevalence of lifetime and current substance use amongst PLWH was 53\% (95\% CI: 47.63 - 58.36) and 32.3\% (95\% CI: $27.44-37.52)$, respectively. The lifetime substance used most often was alcohol (47.8\%), followed by tobacco (29.7\%), cannabis $(5.7 \%)$ and other substances $(2.9 \%)$. The highest prevalence of substance use occurred in the 18-30-year-old age group. The prevalence of substance use decreased with advancing age and a statistically significant difference was observed with different age group participants (lifetime user $\chi^{2}=18.3, p=0.001$, current user $\chi^{2}=11.0, p=0.012$ ).

The prevalence of lifetime substance uses amongst male $(84 \%)$ participants is twice as high as amongst their female $(41 \%)$ counterparts $\left(\chi^{2}=57.3, p<0.001\right)$. The prevalence of current substance uses amongst male (65\%) participants is three times higher than that of their female (21\%) counterparts

TABLE 1: Demographic and clinical characteristics of lifetime and current substance use amongst people living with HIV in Mthatha, South Africa ( $n=347)$.

\begin{tabular}{|c|c|c|c|c|c|c|c|c|c|}
\hline \multirow[t]{2}{*}{ Variable } & \multirow{2}{*}{$\begin{array}{c}\text { Total } \\
\text { population }\end{array}$} & \multicolumn{4}{|c|}{ Lifetime substance use } & \multicolumn{4}{|c|}{ Substance use in the last 3 months } \\
\hline & & $n$ & $\%$ & $\chi^{2}$ & $p$ & $n$ & $\%$ & $\chi^{2}$ & $p$ \\
\hline Age (years) ( $n=347$ ) & - & - & - & 18.3 & $<0.001^{*}$ & - & - & 11.0 & $0.012 *$ \\
\hline $18-30$ & 88 & 62 & 67.4 & - & - & 41 & 44.6 & - & - \\
\hline $31-40$ & 129 & 69 & 53.5 & - & - & 41 & 31.8 & - & - \\
\hline $41-50$ & 87 & 31 & 35.6 & - & - & 19 & 21.8 & - & - \\
\hline Above 50 & 39 & 22 & 56.4 & - & - & 11 & 28.2 & - & - \\
\hline Total & - & 184 & - & - & - & 112 & - & - & - \\
\hline Gender $(n=347)$ & - & - & - & 57.3 & $<0.001 *$ & - & - & 56.4 & $<0.001^{*}$ \\
\hline Male & 86 & 76 & 84.4 & - & - & 56 & 65.1 & - & - \\
\hline Female & 261 & 108 & 41.4 & - & - & 56 & 21.5 & - & - \\
\hline Total & - & 184 & - & - & - & 112 & - & - & - \\
\hline Occupation ( $n=347)$ & - & - & - & 0.017 & 0.895 & - & - & 0.163 & 0.393 \\
\hline Employed & 101 & 53 & 52.5 & - & - & 31 & 30.7 & - & - \\
\hline Unemployed & 246 & 131 & 53.3 & - & - & 81 & 32.9 & - & - \\
\hline Total & - & 184 & - & - & - & 112 & - & - & - \\
\hline Education status ( $n=345)$ & - & - & - & 2.6 & 0.268 & - & - & 0.676 & 0.713 \\
\hline Primary school & 35 & 23 & 65.7 & - & - & 10 & 28.6 & - & - \\
\hline High school & 294 & 151 & 51.4 & - & - & 96 & 33.0 & - & - \\
\hline Degree or diploma & 16 & 8 & 50.0 & - & - & 4 & 25.0 & - & - \\
\hline Total & - & 182 & - & - & - & 110 & - & - & - \\
\hline Per capita household income $(n=344)$ & - & - & - & 0.522 & 0.770 & - & - & 0.411 & 0.814 \\
\hline Less than R532.00† & 258 & 140 & 54.3 & - & - & 84 & 32.6 & - & - \\
\hline R532 to R1138.00 & 31 & 15 & 48.4 & - & - & 11 & 35.5 & - & - \\
\hline$>$ R1138.00 & 55 & 28 & 50.9 & - & - & 16 & 29.1 & - & - \\
\hline Total & - & 183 & - & - & - & 110 & - & - & - \\
\hline Disclosure of HIV $(n=328)$ & - & - & - & 2.07 & 0.557 & - & - & 6.33 & 0.097 \\
\hline Friends & 19 & 9 & 47.4 & - & - & 7 & 36.8 & - & - \\
\hline Life partner & 78 & 45 & 57.7 & - & - & 31 & 39.7 & - & - \\
\hline Family member & 231 & 118 & 51.3 & - & - & 63 & 27.8 & - & - \\
\hline Total & - & 173 & - & - & - & 102 & - & - & - \\
\hline CD4 counts ( $n=292$ ) & - & - & - & 1.3 & 0.86 & - & - & 8.3 & 0.08 \\
\hline Less than 50 & 21 & 12 & 57.1 & - & - & 6 & 28.6 & - & - \\
\hline 50-100 & 19 & 8 & 42.1 & - & - & 6 & 31.6 & - & - \\
\hline $101-200$ & 40 & 19 & 47.5 & - & - & 4 & 10.0 & - & - \\
\hline $201-500$ & 100 & 53 & 53.0 & - & - & 33 & 33.0 & - & - \\
\hline More than 500 & 112 & 56 & 50.0 & - & - & 32 & 28.6 & - & - \\
\hline Total & - & 142 & - & - & - & 81 & - & - & - \\
\hline Viral load $(n=106)$ & - & - & - & 0.123 & 0.726 & - & - & 0.005 & 0.946 \\
\hline Detectable & 80 & 43 & 53.8 & - & - & 21 & 26.3 & - & - \\
\hline Non-detectable & 26 & 15 & 57.7 & - & - & 7 & 26.9 & - & - \\
\hline Total & - & 58 & - & - & - & 28 & - & - & - \\
\hline
\end{tabular}

$\mathrm{CD} 4$, cluster of differentiation 4

$*, p<0.05$ statistically significant.

$\dagger$, R532 food poverty line (Stat SA 2017).

$\ddagger$, R1138 upper bound of the poverty line (Stat SA 2017). 
$\left(\chi^{2}=56.4, p<0.001\right)$. The majority of PLWH had a CD4 count of more than 200 and there was no statistically significant difference between substance use and CD4 counts.

The prevalence of different substances used by PLWH according to their age category is demonstrated in Figure 3. Alcohol was the most commonly used substance amongst PLWH in all age categories, followed by tobacco, cannabis and other substances.

Table 2 presents the ASSIST risk score for different substances used by PLWH. The mean risk score for tobacco users $(15.4 \pm 7.9)$ was slightly higher than that for alcohol users $(12.1 \pm 7.8)$. About half $(55 \%)$ of alcohol users and four-fifths $(81 \%)$ of tobacco users scored in the moderate risk category. Only seven substance users (ASSIST risk score $>26$ ) were classified as being in the high-risk category of substance use, namely, three alcohol users, three tobacco users and one cocaine user.

\section{Discussion}

Alcohol is the most commonly used substance reported amongst PLWH in PHC facilities. The data reported here document a high lifetime and current prevalence of alcohol abuse. These findings are consistent with a countrywide estimation of substance use and are consistent with the use reported in other sub-Saharan countries. ${ }^{5,19}$ South Africa has one of the highest per capita alcohol consumption rates in the

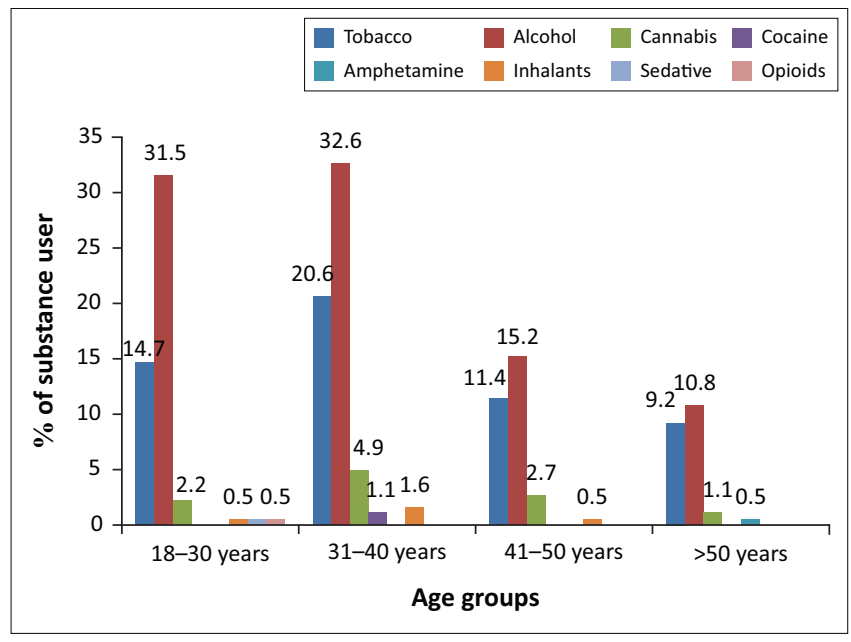

FIGURE 3: Lifetime use of substances amongst people living with human immunodeficiency virus in Mthatha, South Africa $(n=184)$. world. Although many studies reported geographical differences in the prevalence of substance use, alcohol remains the substance used most often by South Africans. ${ }^{20,21}$

The lifetime prevalence of alcohol use (47.8\%) amongst PLWH in this study is much higher than that amongst the general population (38.7\%) as reported by a South African stress and health study. ${ }^{4,22}$ Similar alcohol consumption amongst PLWH was reported in many African countries, such as Zambia (44.3\%), Tongo (40.6\%) and Côte d'Ivoire (46.4\%)..$^{5,20}$ Some studies even demonstrate that the alcohol consumption rates amongst PLWH are almost twice as high as amongst the general population. ${ }^{21}$ Although alcohol consumption is widespread in the general population, hazardous use is much higher amongst PLWH, resulting in decreased overall life expectancy in this group. ${ }^{5}$ The psychological impact of the dual stigma of HIV infection and alcohol consumption hinder health-seeking behaviour for people who are both HIVpositive and substance users. $^{23}$ Substance users amongst PLWH often fail to attend HIV care despite early diagnosis. Even after linkage to care, a poor adherence rate is reported amongst PLWH who use substances.

It is notable that the proportion of lifetime and current substance use was high amongst younger participants than their older counterparts but the findings from the current study could not establish the age of substance use initiation. The national and international research has reported that substance use generally commences at a younger age. ${ }^{14,24}$ Adolescence is a critical period of physical and psychological development when substance use problems and other risktaking behaviour commence. There are many reasons for use of substances amongst adolescents, including desire of a new experience, peer pressure, stress and an attempt to deal with problem. Substance use is generally initiated around the age of 11 years or sometimes even at a younger age. The exact age for substance use screening nevertheless depends on the local prevalence and pattern of substance use..$^{25}$ Because the study demonstrated a high prevalence of substance use amongst PLWH, it is appropriate to commence regular screening at PHC facilities.

The findings reported heavy alcohol consumption amongst males compared with their female counterparts. Higher consumption of alcohol amongst males has been reported both in sub-Saharan Africa and in developed countries in

TABLE 2: Alcohol, Smoking and Substance Involvement Screening Test risk score of current substance use amongst people living with human immunodeficiency virus in Mthatha, South Africa.

\begin{tabular}{|c|c|c|c|c|c|c|c|c|c|c|c|c|}
\hline \multirow[t]{3}{*}{ Variables } & \multicolumn{4}{|c|}{ ASSIST } & \multicolumn{2}{|c|}{$\begin{array}{l}\text { ASSIST risk score } \\
\text { current use }\end{array}$} & \multicolumn{6}{|c|}{ ASSIST risk level of current use $\dagger$} \\
\hline & \multicolumn{2}{|c|}{ Lifetime use } & \multicolumn{2}{|c|}{ Current use } & \multirow{2}{*}{$\begin{array}{l}\text { Mean } \\
\text { score }\end{array}$} & \multirow[t]{2}{*}{ SD } & \multicolumn{2}{|c|}{ Low } & \multicolumn{2}{|c|}{ Moderate } & \multicolumn{2}{|c|}{ High } \\
\hline & $n$ & $\%$ & $n$ & $\%$ & & & $n$ & $\%$ & $n$ & $\%$ & $n$ & $\%$ \\
\hline Alcohol & 166 & 47.8 & 96 & 27.6 & 12.1 & 7.88 & 40 & 41.6 & 53 & 55.2 & 3 & 3.1 \\
\hline Tobacco & 103 & 29.7 & 65 & 18.7 & 15.4 & 7.93 & 9 & 13.8 & 53 & 81.5 & 3 & 4.6 \\
\hline $\begin{array}{l}\text { Other } \\
\text { substances }\end{array}$ & 30 & 8.6 & 4 & 1.1 & 20.75 & 13.93 & 1 & 25 & 2 & 50 & 1 & 25 \\
\hline
\end{tabular}

ASSIST, Alcohol, Smoking and Substance Involvement Screening Test; SD, standard deviation.

$\dagger$, The risk level for alcohol: low $=0-10$, moderate $=11-26$, high $=$ more than 26; for other substances: low $=0-3$, moderate $=4-26$, high $=$ more than 26 .

$\$$ Other substances included cannabis, cocaine, amphetamine, opioids and sedatives. 
North America and Europe. ${ }^{26}$ It is attributed to the acceptance of male drinking as part of the social and masculine norm in many societies, whilst the same societies do not apply these norms for women. Overall, substance use tends to be higher amongst males than amongst females. These findings are consistent with reported research in subSaharan Africa. ${ }^{27,28}$

The majority of PLWH who consume alcohol and other substances are unemployed and living in a household with a per capita income below the food poverty line (R532.00 per capita). Alcohol product in South Africa is more affordable than in most low- and middle-income countries. ${ }^{29}$ This might be a possible explanation of alcohol abuse even in people of low socio-economic status. Similar results were reported in a study based on nationally representative data from South Africa, which stated that the harmful use of alcohol amongst PLWH was much higher amongst people of low socioeconomic status. In contrast, Probst et al. reported that there was no difference in consumption of alcohol amongst PLWH in different socio-economic classes in South Africa, but high $\mathrm{HIV}$-associated mortality and poor clinical outcomes were attributed to low socio-economic status amongst PLWH. ${ }^{30}$ Furthermore, it states that affordability of alcohol products is an important determinant of demand and increase in taxes and prices can limit the consumption and demand of alcoholic products. ${ }^{29}$

The majority of substance users amongst PLWH have a lowto-moderate (score < 27) risk, according to the ASSIST tools. Primary care workers therefore have an ideal opportunity for early intervention before serious substance dependency develops. Many research findings support the notion that low-to-moderate risk of substance use has shown significant improvement when simple motivational interviewing techniques are used. ${ }^{31}$ Furthermore, it is stated that this brief intervention may easily be integrated within context-specific PHC settings. In particular, brief intervention for alcohol use has emerged as a cost-effective and practical approach for PHC settings. These interventions are particularly short in duration and promote positive behavioural changes. Although brief intervention is often not feasible as a treatment on its own for high-risk patients, it provides the foundation for PHC workers for detailed clinical assessments and appropriate specialist referrals. ${ }^{18,21}$

\section{Limitations of the study}

The researchers acknowledge several limitations. The information on substance use was self-reported, which may have compromised its reliability in terms of over-reporting or under-reporting. The study did not use any biomarker or collateral information from family members to verify the use of the substance. Furthermore, the sample is derived from PHC users in a local context and in a selected population of PLWH.

\section{Conclusion}

This study has shown that there is a high prevalence of lifetime and current alcohol abuse amongst PLWH who make use of PHC services in the Mthatha area of South Africa. Of particular concern are the strong pointers towards younger people and males. The age and gender-sensitive policy interventions would need to address these challenges if we would like to reduce the effects of these results on the HIV epidemic in the Mthatha region. Given the high prevalence of substance use amongst PLWH in primary care users indicates the needs of routine screening substance use.

\section{Acknowledgements}

The study was financially supported by the National Research Foundation and an operational research bursary from Stellenbosch University Collaborative Capacity Enhancement through engagement with districts. The authors thank the research assistants, the management, staff of facility and the biostatistician for their support throughout the study.

\section{Competing interests}

The authors declared that no conflict of interest exists.

\section{Authors' contributions}

Dr R.K. performed this research as part of his doctoral studies at Stellenbosch University whilst working as a senior lecturer at Walter Sisulu University. Prof. M.d.V. acted as the principal supervisor for the doctoral study, assisted in the development of the protocol, oversaw the research and contributed to various versions of this article.

\section{Funding information}

This research received no specific grant from any funding agency in the public, commercial or not-for-profit sectors.

\section{Data availability statement}

Data sharing is not applicable to this article as no new data were created or analysed in this study.

\section{Disclaimer}

The views and opinions expressed in this article are those of the authors and do not necessarily reflect the official policy or position of any affiliated agency of the authors.

\section{References}

1. UNODC. World drug report 2016 [homepage on the Internet]. United Nations Publication, Sales No. E.16.XI.7; 2016 [cited 2019 Sept 5]. Available from: https:// www.unodc.org/doc/wdr2016/WORLD_DRUG_REPORT_2016_web.pdf

2. South Africa. Department of Social Development. National drug master plan (NDMP) 2013-2017 of South Africa [homepage on the Internet]. 2013 [cited 2019 Oct 5]. Available from: http://www.dsd.gov.za/index2.php?option=com docman\&task=doc_view\&gid $=414 \&$ Itemid $=3$

3. UNODC. World drug report: Pre-briefing to the member states [homepage on the Internet]. Vienna: United Nations Office on Drugs and Crime; 2018 [cited 2018 June 20]. Available from: https://www.unodc.org/wdr2018/prelaunch/PrebriefingAM-fixed.pdf 
4. Ogden T, Hagen KA. Alcohol and drug use. In: Adolescent mental health. 2nd ed. Milton Park: Routledge, 2018; p. 100-124. https://doi.org/10.4324/9781315295374-5

5. Bultum JA, Yigzaw N, Demeke W, Alemayehu M. Alcohol use disorder and associated factors among human immunodeficiency virus infected patients attending antiretroviral therapy clinic at Bishoftu General Hospital, Oromiy region Ethiopia. PLoS One 2018.13(3):e0189312. https://doi.org/10.1371/ journal.pone.0189312

6. Hartzler B, Donovan D, Beadnell B, et al. Domestic prevalence of substance use disorders in HIV care settings. Drug Alcohol Depend. 2017;171(2017):e84. https:// doi.org/10.1016/j.drugalcdep.2016.08.237

7. Crane HM, Mccaul ME, Chander G, et al. Prevalence and factors associated with hazardous alcohol use among persons living with HIV across the US in the current era of antiretroviral treatment. AIDS Behav. 2018;21(7):1914-1925. https://doi. org/10.1007/s10461-017-1740-7

8. Hartzler B, Dombrowski JC, Crane HM, et al. Prevalence and predictors of substance use disorders among HIV care enrollees in the United States. AIDS Behav. 2017;21(4):1138-1148. https://doi.org/10.1007/s10461-016-1584-6

9. Idrisov B, Lunze K, Cheng DM, et al. Role of substance use in HIV care cascade outcomes among people who inject drugs in Russia. Addict Sci Clin Pract. 2017;12(1):30. https://doi.org/10.1186/s13722-017-0098-5

10. Mayer KH, Meyer JP, Althoff AL, Altice FL. Optimizing care for HIV-infected people who use drugs: Evidence-based approaches to overcoming healthcare disparities. Clin Infect Dis. 2013;57(9):1309-1317. https://doi.org/10.1093/cid/cit427

11. Granich RM, Gilks CF, Dye C, De Cock KM, Williams BG. Universal voluntary HIV testing with immediate antiretroviral therapy as a strategy for elimination of HIV transmission: A mathematical model. Lancet. 2009;373(9657):48-57. https://doi.org/10.1016/S0140-6736(08)61697-9

12. Deren S, Cortes T, Dickson VV, et al. Substance use among older people living with HIV: Challenges for health care providers. Front Public Heal. 2019;7:1-10. https://doi. org/10.3389/fpubh.2019.00094

13. Nolan S, Walley AY, Heeren TC, et al. HIV-infected individuals who use alcohol and other drugs, and virologic suppression. AIDS Care. . Heslop K, Ross C, Osmond B, et al. 2017;29(9):1129-1136. https://doi.org/10.1080/09540121.2017.1327646

14. McNeely J, Kumar PC, Rieckmann T, et al. Barriers and facilitators affecting the implementation of substance use screening in primary care clinics: A qualitative study of patients, providers, and staff. Addict Sci Clin Pract. 2018;13(1):8. https:// doi.org/10.1186/s13722-018-0110-8

15. Dawson-Rose $C$, Draughon JE, Zepf $R$, et al. Prevalence of substance use in an HIV primary care safety net clinic: A call for screening. J Assoc Nurses AIDS Care. 2017;28(2):238-249. https://doi.org/10.1016/j.jana.2015.12.001

16. Humeniuk RE, Henry-Edwards S, Ali R, et al. Brief intervention: The ASSIST-linked brief intervention for hazardous and harmful substance use: Manual for use in primary care [homepage on the Internet]. World Health Organization; 2010 [cited 2019 May 11]; p. 46. Available from: http://www.who.int

17. Rogerson $\mathrm{CM}$. Peripheral tourism trajectories: Evidence from the King Sabata Dalindyebo Municipality, South Africa. Geoj Tour Geosites. 2019;26(3):974-992. https://doi.org/10.30892/gtg.26323-411

18. Heslop K, Ross C, Osmond B, et al. The Alcohol, Smoking and Substance Involvement Screening Test (ASSIST) in an Acute Mental Health Setting. Int J Mental Health Addict. 2013;11:583-600. https://doi.org/10.1007/s11469-013-9428-3
19. Needle RH, Kroeger K, Belani H, Hegle J. Substance abuse and HIV in Sub-Saharan Africa. African J Drug Alcohol Stud. 2006;5(1):1-2.

20. Nouaman $M N$, Vinikoor $M$, Seydi $M$, et al. High prevalence of binge drinking among people living with HIV in four African countries. J Int AIDS Soc. 2018;21(12):e25202. https://doi.org/10.1002/jia2.25202

21. Vellios NG, Van Walbeek CP. Self-reported alcohol use and binge drinking in South Africa: Evidence from the National Income Dynamics Study, 2014-2015. S Afr Med J. 2017 [cited 2019 May 5];108(1):33. Available from: http://www.samj.org.za/index $\mathrm{php} / \mathrm{samj} /$ article/view/12170

22. Ramlagan S, Peltzer K, Matseke G. Epidemiology of drug abuse treatment in South Africa. S Afr J Psychiatr. 2010;16(2):40-49. https://doi.org/10.4102/sajpsychiatry. v16i2.172

23. O'Leary B, Strike C, Rohailla S, et al. Perspectives of healthcare workers about the delivery and evaluation of harm reduction services for people living with HIV who use substances. Cogent Med. 2018;5(1):1-10. https://doi.org/10.1080/233120 5X.2018.1461005

24. Dos Santos R., Hallak JEC, Zuardi AW, Crippa JAS. International standards for the treatment of drug use disorders. Handb Cannabis Relat Pathol [serial online] 2017 [cited 2019 May 5];01463:94. Available from: https://www.who.int/substance abuse/activities/msb_treatment_standards.pdf

25. Scott-Sheldon LAJ, Carey KB, Johnson BT, Carey MP. Behavioral interventions targeting alcohol use among people living with HIV/AIDS: A systematic review and meta-analysis. AIDS Behav. 2017;21(S2):126-143. https://doi.org/10.1007/s10461 017-1886-3

26. Das JK, Salam RA, Arshad A, Finkelstein Y, Bhutta ZA. Interventions for adolescent substance abuse: An overview of systematic reviews. J Adolesc Heal [serial online]. 2016 [cited 2019 July 10];59(4):S61-S75. Available from: https:// linkinghub.elsevier.com/retrieve/pii/S1054139X16301677

27. Wandera B, Tumwesigye NM, Nankabirwa JI, et al. Alcohol consumption among HIV-infected persons in a large urban HIV clinic in Kampala Uganda: A constellation of harmful behaviors. PLoS One. 2015:10(5):0126236. https://doi.org/10.1371/ journal.pone.0126236

28. Baum MK, Campa A, Page JB, Lai S, Tsalaile L. Recruitment, follow-up and characteristics of HIV infected adults who use illicit drugs in Southern Africa. J Drug Abuse [serial online]. 2015 [cited 2019 May 8];01(01):1-9. Available from: http://drugabuse.imedpub.com/recruitment-followup-and-characteristics-of-hivinfected-adults-who-use-illicit-drugs-in-southern-africa.php?aid=7770

29. Van Walbeek $C$, Blecher $E$. The economics of alcohol use, misuse and policy in South Africa [homepage on the Internet]. World Health Organization; 2014 [cited 2019 June 15]. Available from: http://tobaccoecon.org/wp-content/uploads/2014/03/ the-economics-of-alcohol-policy-in-south-africa.pdf

30. Probst C, Simbayi LC, Parry CDH, Shuper PA, Rehm J. Alcohol use, socioeconomic status and risk of HIV infections. AIDS Behav [serial online]. 2017;21(7):19261937. https://doi.org/10.1007/s10461-017-1758-x

31. Smedslund G, Berg RC, Hammerstrøm KT, et al. Motivational interviewing for substance abuse. Cochrane Database Syst Rev [serial online]. 2011 [cited 2019 July 9];(5):CD008063. Available from: https://www.cochranelibrary.com 